\title{
Lamp Design from Wasted Fabric in Garment Industry
}

\author{
Jong Boonpracha ${ }^{1} \&$ Somsakul Jerasilp ${ }^{1}$ \\ ${ }^{1}$ Faculty of Industrial Technology, Suan Sunandha Rajabhat University, Bangkok, Thailand \\ Correspondence: Jong Boonpracha, Faculty of Industrial Technology, Suan Sunandha Rajabhat University, \\ Thailand. Tel: 6-685-834-4659. E-mail: jong.bo@ssru.ac.th
}

Received: July 7, 2019 Accepted: July 21, $2019 \quad$ Online Published: September 29, 2019

doi:10.5539/ass.v15n10p36

URL: https://doi.org/10.5539/ass.v15n10p36

\begin{abstract}
Garment Industry is one of the industries that have dumped a large amount of wasted fabric at least 30-40 kg / month. Wasted fabrics are caused by the process of sewing, hydraulic pumping, and flaws on fabric. Those wastes were not being used for any further utilization. The current work investigated the use of Upcycling, a process to converse waste material to become a new product with higher quality and environmentally friendly value, as a conceptual model in the design process and examined its value for Upcycling product design by looking at a case study project. The concept from the Upcycling framework study was chosen for the investigation in order to evaluate a case study: a wasted fabric lamp. The findings suggest that Upcycling was helpful for improving and developing a wasted fabric lamp throughout the design process: including idea development, decision making, and implementation. Based on the evaluation of 3 design experts, it was found that a wasted fabric lamp is appropriate for using new materials or raw materials that do not cause problems for the environment.
\end{abstract}

Keywords: lamp design, wasted fabric, garment industry

\section{Introduction}

At present, the manufacturing sector in various industries needs a lot of resources and materials to produce products to meet the increasing demand. Garment and Textiles productions are among the industries that contribute most negatively to environmental and social aspects of sustainability (Madsen, Hartlin, Perumalpillai, Selby, \& Aumônier, 2015). The manufacturers have to accelerate the creation of new products to meet the needs of the growing consumer all the time. Therefore, it is not surprising that the waste from the manufacturing sector will occur continuously and became a problem that still could not find a concrete solution. The problem of waste materials from the manufacturing sector still has no clear solution. Resolving problems is just a debate that has not yet been finalized partly because the manufacturers themselves overlook the importance of efficient waste management.

To reduce negative environmental impacts in waste materials from the manufacturing sector, there has been increased focus on the Upcycle. The design and production process have focused on the process of reuse materials to make the quality higher than the original. Surveying various manufacturing sectors for waste disposal from Smile resource exchange (2015) found that Upcycle was becoming very popular among those manufactories. 82 percent impress this concept because it is seen as a cost reduction in terms of production and garbage disposal and also increase efficiency promote corporate image that is responsible for the environment. Two out of three of these manufactories trended to develop the management of works from their own wastes.

The current work presents a case study involving the creation of a product from waste fabric. A procedure for improving the current of the application of Upcycle in the design process would require creating design outcomes, a research method carried out bringing waste fabric designed to be a new product with higher quality. The case study showed how designer develop a model based on Upcycle concept.

\section{Upcycle for Product Design from Waste Materials}

Upcycle is the process of converting waste materials or products that cannot be used according to the previous function to be a useful new product with added value or more beautiful. Upcycle is designed to resist the shopping culture but encourage consumers to rethink using new things in the most worthwhile remaining instead of buying new consumer products for the benefit of the overall environment. 
Upcycle may look similar to Recycle but both concepts have different methods. Recycle is to make things that can't be used again or may have been broken back into the processing process. Most of the methods are used to melt into the original material or produce a new item which may have inferior quality or value. In the process of processing, it must use energy or use chemicals to transform and have costs related to the environment. On the other hand, Upcycle is a process that uses creative ideas and design into new items through the process of converting to use minimum energy or chemical processes.

In 2010, Market survey data (Fiksel, 2011) showed that consumers tend to spend more on eco-friendly products. More than 70 percent of consumers in China, India and Brazil tend to buy environmental products. In addition, on the demand for environmental products around the world, More than 60 percent of consumers have a desire to buy products from companies or organizations that pay more attention to the environment.(Ferraris \& Paleari, 2013) In 2013, the Department of Environmental Quality Promotion has developed criteria for evaluating products created from waste materials to support entrepreneurs who use waste materials to produce products as a substitute material or create a new product (Figueiredo \& Guillen, 2014).

Based on previous studies (Sangjanthai \& Phirasan, 2015; Panaputtikul, Boonthumchoy, \& Porncharoen, 2013; Laitala \& Klepp, 2013) this paper offers a framework for studying product design from Upcycle,as summarized in Figure 1, in which a process can be classified into three layers: (1) Design; the first priority step to consider not creating waste. (2) Manufacturing; the second step to minimize the amount of waste materials and (3) Waste disposal; the last step to reuse as much as possible.

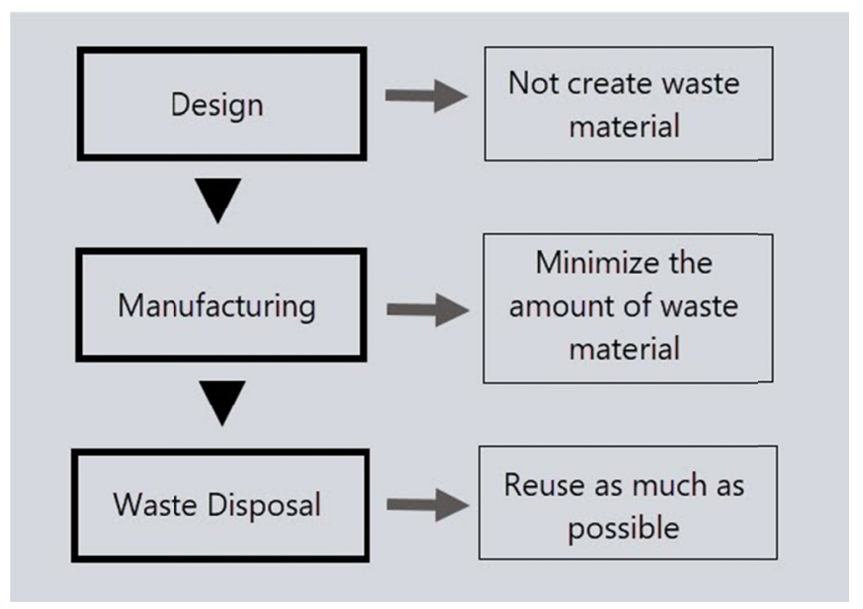

Figure 1. framework for studying product design from Upcycle

\section{Research Objectives}

(1) To study the process of utilizing wasted fabric in garment industry

(2) To improve the utilization of wasted fabric in garment industry.

(3) To design prototype products from wasted fabric according to design for sustainability concept

(4) To evaluate consumer satisfaction on prototype products.

\section{Research Methodology}

\subsection{Research Procedure}

Stage 1: Investigating general situation of wasted fabric in garment industry by searching documents, texts, research, and websites for relevant information. Interviews were conducted with Medium-sized fabric processing industry operators producing ready-made fashion clothes and fabric processing community enterprise.

Stage 2: Collecting field data under the conceptual framework derived from documentary study and websites.

Stage 3: Examine data on general situation of wasted fabric in garment industry to guide the utilization of wasted fabric product design.

Stage 4: Design and create on focusing on utilization of wasted fabric by collecting information as baseline data to design wasted fabric products.

Stage 5: Conclude, discuss, and recommend on descriptive analysis of field data according to the theme. 


\subsection{Scope of Research}

Stage 1: To study the process of utilizing wasted fabric in garment industry

Population: Medium-sized textile factories for ready-made clothing

Sample: Medium-sized fabric processing industry operators producing ready-made fashion clothes and fabric processing community enterprise.

Stage 2: To improve the utilization of wasted fabric in garment industry

Population: Medium-sized textile factories for ready-made clothing

Sample: Medium-sized fabric processing industry operators producing ready-made fashion clothes and fabric processing community enterprise.

Stage 3: To design prototype products from wasted fabric according to design for sustainability concept

Population: Product design experts

Sample: 3 industrial fabric design experts

Stage 4: To evaluate consumer satisfaction from product design of waste fabric

Population: Consumers who were interested in industrial fabric design

Sample: 100 Consumers who visited in OTOP product showroom and distribution in Thanya Park Mall, Bangkok, Thailand by December 25, 2018.

\section{Results}

\subsection{Utilization of Wasted Fabric}

The amount of discarded waste from industrial processes was $30-40 \mathrm{~kg} /$ month which can be categorized as waste fabric of

(1) wasted fabric from sewing

(2) wasted fabric from the pump with hydraulic machine

(3) wasted fabric from fabric defects

The opinions of entrepreneurs for the utilization of wasted fabric in garment industry are divided into 3 characteristics according to sustainable design guidelines.

\subsubsection{Reduce Material}

Entrepreneurs have a great deal of opinion in order to maximize the use of waste cloth from the processed fabric industry through any processing process so that the residual waste is less than the original and create added value for small waste to transform into products. The use of these wastes to be used to create value Will make a lot of products While losing the same material That is to reduce waste materials And get more value products Resulting in cost savings And create added value for the product.

\subsubsection{Reuse Material}

Entrepreneurs have a great deal of opinion in bringing waste from industrial processes. Forming with various processes to bring them back to use again. Scraps that have been used should be used again and again whether it is the appearance of the rag caused by scrap from sewing or damaged .Taking advantage of these rags is a necessary process for thinking about the process of scrap fabric to be the most useful product

\subsubsection{Recycle Material}

In the process of recycle materials, it is found that the operators have a need to use the materials after processing with various processes in a systematic manner In order to be able to use the material more valuable Can use waste materials and materials that have been used and then return again Where the process is not complicated in cost and time With simplicity and novelty, combined with appropriate equipment.

\subsection{Development of the Utilization of Wasted Fabric}

The process of utilizing waste fabric to be a guideline for product development can summarize the process as follows

- Gluing fabric sheets 


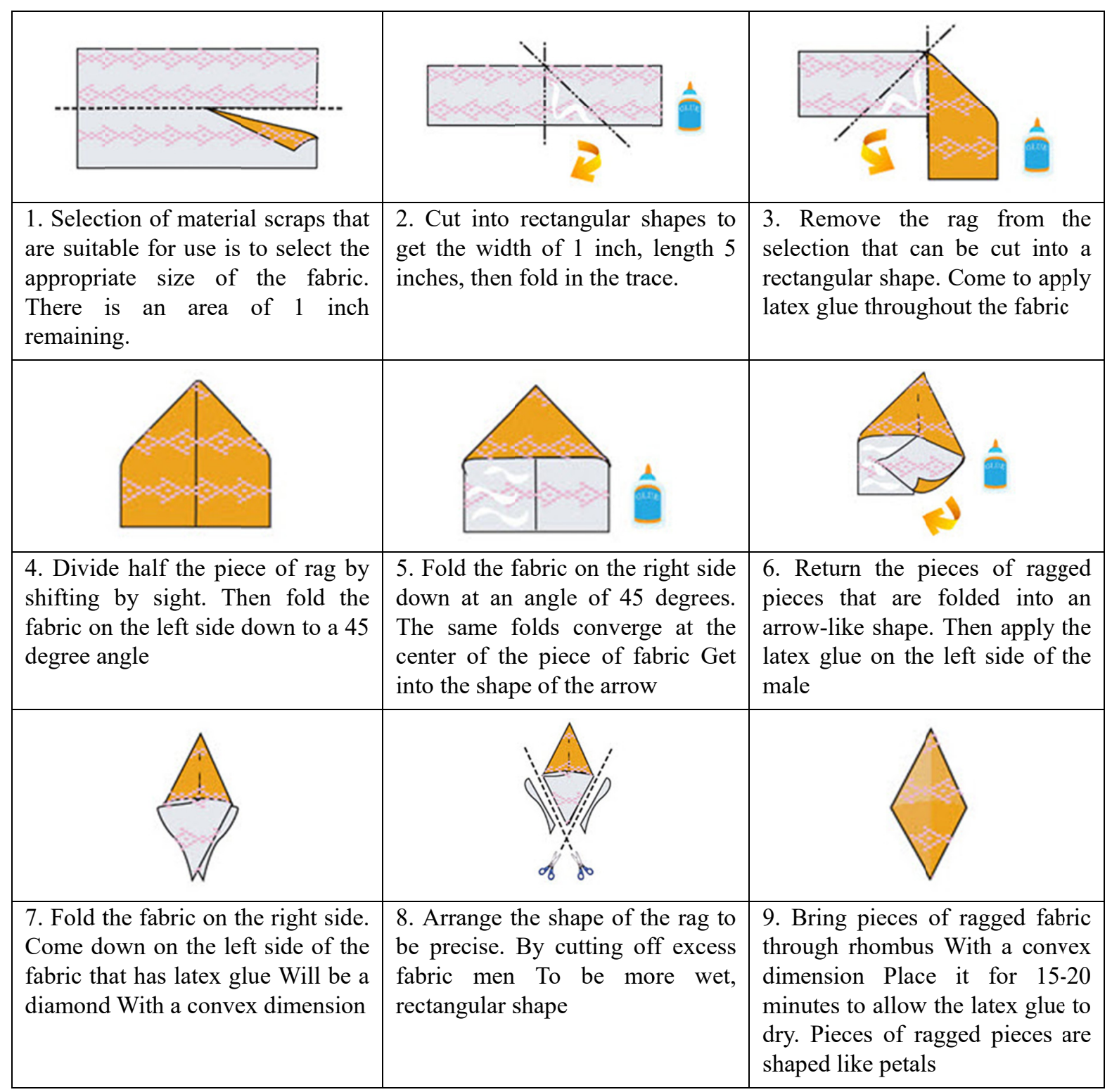

Figure 2. process of bringing wasted fabric to be folded and glued to be geometric form of diamond shape

Sewing fabric sheets

\begin{tabular}{|l|l|l|}
\hline $\begin{array}{l}\text { 1. Selection of material scraps } \\
\text { that are suitable for use is to } \\
\text { select the appropriate size of the } \\
\text { fabric. There is an area of } 1 \text { inch } \\
\text { remaining. }\end{array}$ & $\begin{array}{l}\text { 2. Create a rectangular shape } \\
\text { block. With a width and length of } \\
\text { shape is most suitable. Both in } \\
\text { the glue sticking for proper } \\
\text { stitching }\end{array}$ & $\begin{array}{l}\text { 3. bringing the ends of the } \\
\text { fabric on both sides to fold } \\
\text { down to flatter the middle of } \\
\text { the fabric }\end{array}$ \\
\hline
\end{tabular}




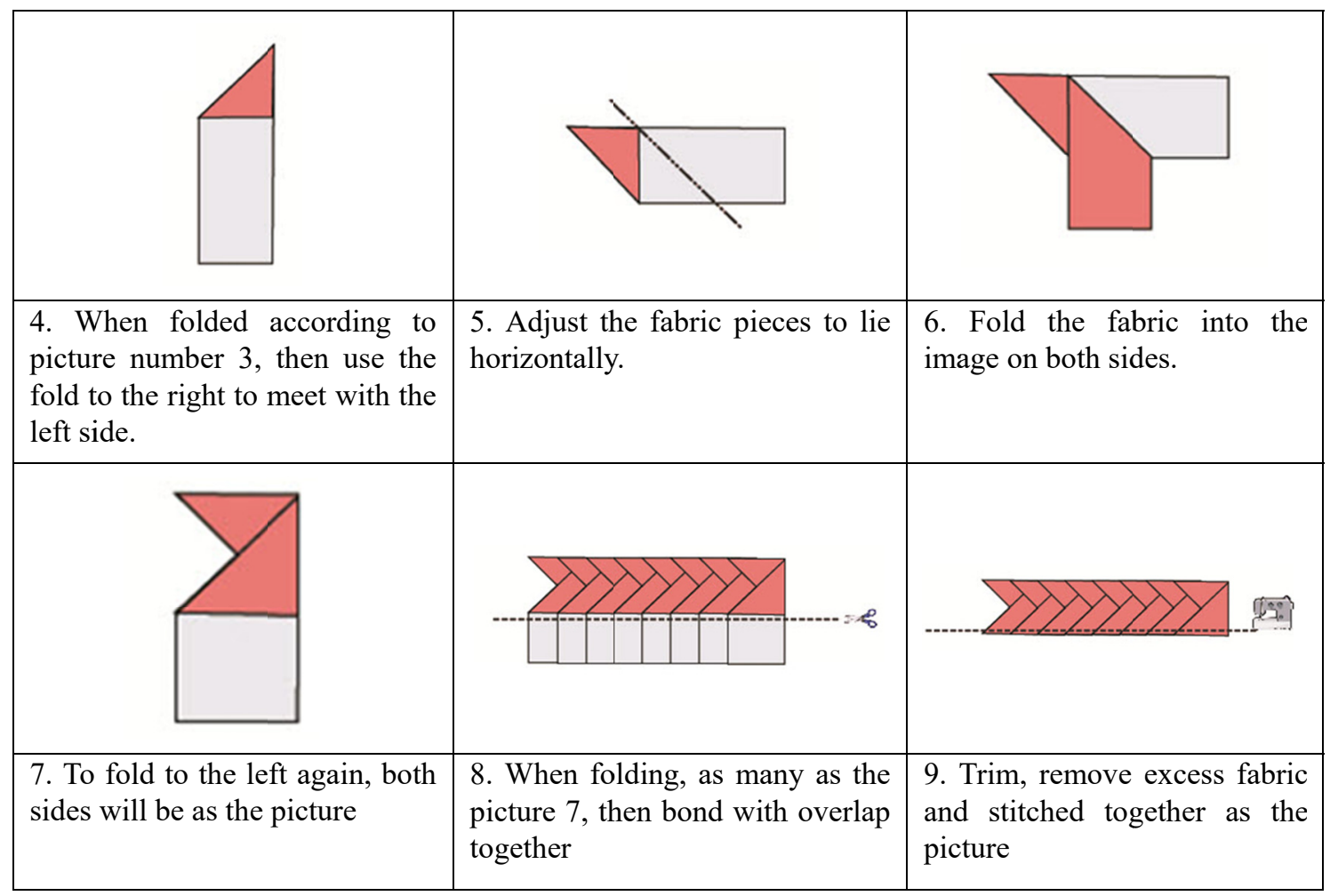

Figure 3. process of sewing a particular piece of fabric

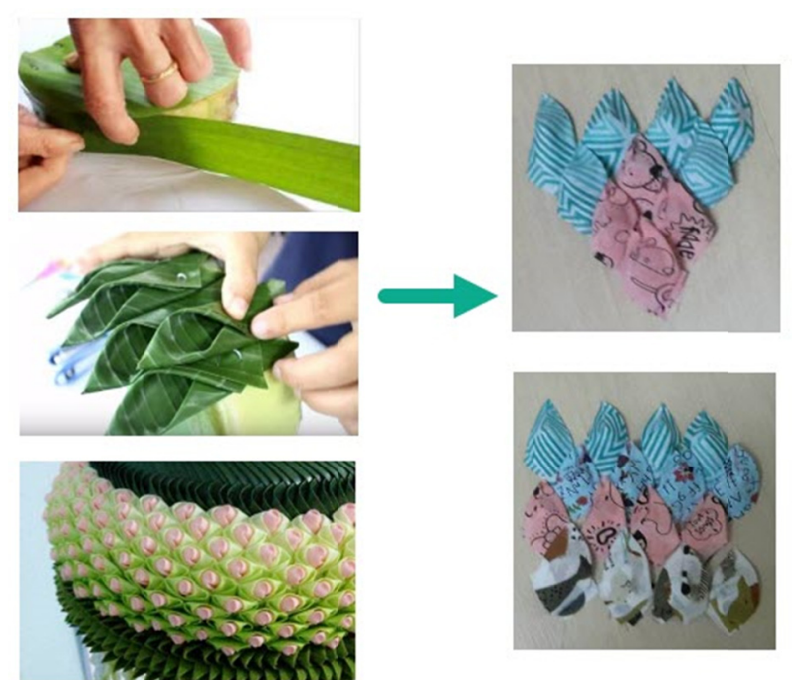

Figure 4. The assembly of waste rag from the concept of Thai cultural product
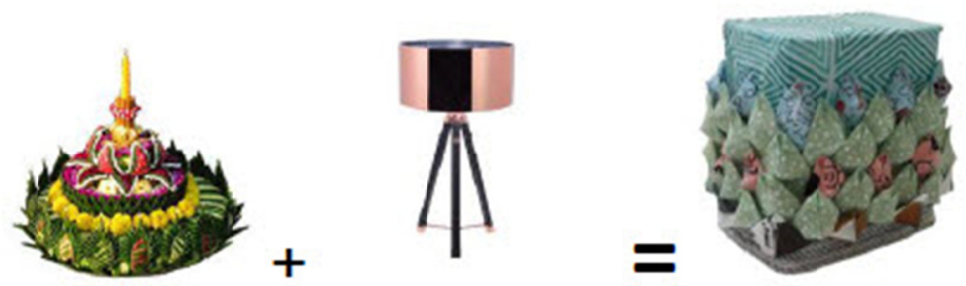

Figure 5. The combination of ideas between a cultural product and a lamp to be a product from waste fabric 

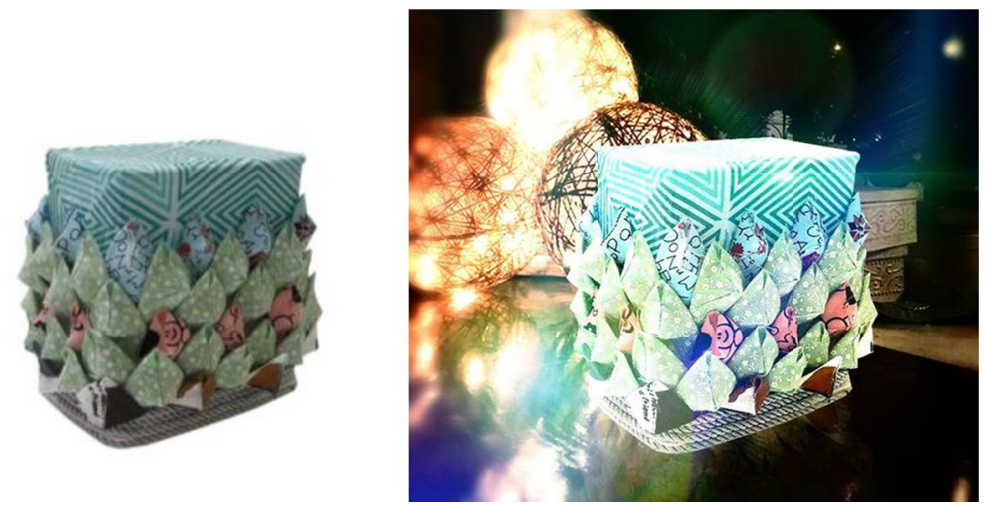

Figure 6. A prototype lamp from waste fabric in garment industry

Table 1. Test result of Consumer satisfaction assessment with a product

\begin{tabular}{|c|c|c|c|c|}
\hline \multirow{2}{*}{$\begin{array}{l}\text { Examined } \\
\text { Feature }\end{array}$} & \multirow{2}{*}{ Specified Criteria } & \multicolumn{2}{|c|}{ Test result } & \multirow{2}{*}{ Interpretation } \\
\hline & & $\overline{\mathrm{X}}$ & S.D. & \\
\hline Novelty & the quality of being new which attracts people's attention and interest & 3.70 & 0.46 & Excellent \\
\hline Aesthetic & attractive appearance & 4.00 & 0.49 & Excellent \\
\hline Material & $\begin{array}{l}\text { Using new materials or raw materials that do not cause problems for the } \\
\text { environment }\end{array}$ & 4.09 & 0.64 & Excellent \\
\hline Function & Suitable for use along with environmentally friendly & 3.85 & 0.53 & Excellent \\
\hline \multirow[t]{2}{*}{ Production } & Easy to produce and there is no complicated procedure & 3.68 & 0.45 & Excellent \\
\hline & Total & 3.86 & 0.51 & Excellent \\
\hline
\end{tabular}

As suggested in Table 1. The overall features of the product meet the criteria with a total score of 3.86 all at excellent level. The highest score was for material followed by aesthetic, function, novelty, and production respectively

\section{Discussion}

The study of the process of reusing materials from the production waste in the factory show that there is a large amount of waste left over from the production process. As that result, the community operators are of the opinion that waste should be taken to be used as a new product again by using the process to bring those waste materials to produce new ones to create additional value. According to Singhashuto (2015), noted that manufacturers often neglect to study, learn and develop the process of reuse. Therefore they chose to destroy debris which were considered a business opportunity and reduce the opportunity to stimulate the economy of the country. Although the problem of waste management from the manufacturing sector by various methods of disposal is a difficult problem that can be resolved soon. However, if considered creatively, it is found that the debris is not necessary to wait for disposal but can be used to create additional value by applying it back to create a new product that responds to market demand. This method not only helps to reduce the amount of material waste from the manufacturing sector effectively, it can also reduce other problems that come with the removal of non-standard waste and also help to create another income as well.

The results of the research showed that The process of reusing materials from production waste in the factory was suitable for the use of raw materials and environmentally friendly, modern novelty, but should be developed to increase the market competitiveness which corresponds to Aumpai Saengchanthai (2015) studying the development of furniture from water hyacinth of the Wong Kong Gong water hyacinth group at Lan Krabue district, Khampangphet, Thailand. To develop new products from water hyacinth products, an important factor in the design of research was the selection of materials, production processes and mechanic skills to apply for the promotion of community economy. Furthermore, this research is consistent with Nataphong Panuphikul (2012, 20) studied the construction of furniture products from shell cladding materials to promote professional value addition of the Ubonratana Dam community with the concept of presenting contemporary styles. By applying the concept of using cement materials, the design was easy to use, consistent with the needs of the contemporary market coupled with the art of furniture design, using the patterns from the art of Isaan that represent the identity 
of the Northeast region. Additionally, the analist considered the possibility of production as a core in the form that has synthesized the needs of the consumer market that was a positive data basis in the same direction.

\section{Conclusion}

The case study showed that Upcycle is a way to handle the problem of waste materials from the manufacturing sector with a large volume by using thinking creatively to change the waste materials to be a new higher quality product. Upcycle is a concept that covers both reuse and recycle. The goal is to be friendly and fair to society, environment and consumers throughout the product life cycle.

In terms of future research, it would be interesting to investigate the way in using different design processes to create different waste material. One aspect to examine would be sustainable design concepts by focusing on creating identity in the product that will be a way to make a difference in products and maintain local identity simultaneously. This will be the basic basis for creating branding and identity in the form of products and as a guideline for creating outstanding products along with being environmentally friendly.

\section{References}

Brenner, T., Achayuthakan, P., \& Nishinari, K. (2013). Linear and Nonlinear Rheology of Mixed Polysaccharide Gels. Pt. I. Young's Modulus, Ring Extension and Uniaxial Compression Tests. Journal of Texture Studies, 44(1), 66-74. https://doi.org/10.1111/j.1745-4603.2012.00366.x

Ferraris, M., \& Paleari, S. (2013). Munipical waste management in Italy. Retrieved July 1, 2014, from http://www.eea.europa.eu/publications/managing-municipal-solid-waste/italy-municipal-waste-management

Indrachuto, S. (2013). Upcycling; Creative wasted material Development. Bangkok: National Science and Technology Development Association.

Laitala, K., \& Klepp, I. G. (2013). Environmental and ethical perceptions related to clothing labels among Norwegian consumers. Research Journal of Textile and Apparel, 17(1). https://doi.org/10.1108/RJTA-17-01-2013-B005

Lertpaiwan S. (2008). Fabric Design. Bangkok: Fashion Study and Development Center, Srinakharinwirot University.

Madsen, J., Hartlin, B., Perumalpillai S., Selby, S., \& Aumônier, S., (2015). Sustainable Development That Occur in Life Cycles of Clothing. London, UK: Chelsea School of Art \& Design.

Panaputtikul, N., Boonthumchoy, P., \& Porncharoen, R. (2013). Garden Furniture Design through the Utilization of Clam Shell Materials. Art and Architecture Journal Naresuan University, 3(2), 19-32.

Pigueiredo, J. N., \& Guillen M. P. (2011). Green Products: Perspectives on Innovation and Adoption. CRC Press: Taylor \& Prancis.

Sangjanthai A., \& Phirasan, J. (2015). Product Development of Water Hyacinth Furniture of Ban Wongklong Group, Lankrabue District, Kamphaegphet Province. Art and Architecture Journal Naresuan University, 6(2), 165-178.

Smile Resource Exchange. (2015). Trash or Treasure? Survey results indicate Upcycling is becoming the Growing Green Trend. Retrieved March 20, 2017, from http://www.smileexchange.ie/news/trash-ortreasure-survey-results-indicate-upcycling-is-becoming-the-growing

\section{Copyrights}

Copyright for this article is retained by the author(s), with first publication rights granted to the journal.

This is an open-access article distributed under the terms and conditions of the Creative Commons Attribution license (http://creativecommons.org/licenses/by/4.0/). 